\title{
Sports participation styles revisited: A time-trend study in Belgium from the 1970s to the 2000s
}

International Review for the Sociology of Sport

2015, Vol. 50(I) 45-63

(C) The Author(s) 2013

Reprints and permissions:

sagepub.co.uk/journalsPermissions.nav DOI: $10.1177 / 1012690212470823$

irs.sagepub.com

\section{Julie Borgers}

University of Leuven, Belgium; Policy Research Centre on Sports, Belgium

\section{Erik Thibaut}

University of Leuven, Belgium

\section{Hanne Vandermeerschen}

University of Leuven, Belgium

\section{Bart Vanreusel}

University of Leuven, Belgium

\section{Steven Vos}

University of Leuven, Belgium; Fontys University of Applied Sciences, The Netherlands

\section{Jeroen Scheerder}

University of Leuven, Belgium

\begin{abstract}
Social changes have been influencing determinants for sports participation since the introduction of the Sport for All ideology in the early 1970s. Consistent with Crum's sportisation theory, today's modes of sports practices, as well as the network of sport services, have diversified and de-traditionalised.
\end{abstract}

\section{Corresponding author:}

Jeroen Scheerder, Policy in Sports \& Physical Activity Research Group, Faculty of Kinesiology and Rehabilitation Sciences, University of Leuven, Gymnasium, Tervuursevest I0I - Bus I500, B-300I Leuven, Belgium.

Email: Jeroen.Scheerder@faber.kuleuven.be 
As part of a research tradition, this contribution aims at analysing changes in sports participation styles in kinesiology students in Belgium during the past four decades (1972-2009). The distinct target group was supposed to fulfil a trend-setting role in the area of active sports participation. Data were obtained from a standardised retrospective questionnaire on leisure-time sports participation. Using standardised methods, Principal Component Analysis was used to identify patterns of sports participation. The results show a diversification of sports participation styles until the 1980s, followed by an intensification of basic style components since the 1990s. Sports participation styles between 1999 and 2009 are subdivided into multiple distinct traditional and non-traditional components, with growing emphasis on non-traditional, alternative practices. Newly observed components in 2009 are discussed in relation to previous time intervals and trends in sports participation.

\section{Keywords}

de-traditionalisation, market segmentation, sportisation, sports participation styles, trend setters

\section{Introduction}

The legitimation of the Sport for All ideology in Europe in the 1970s (Council of Europe, 1975) has generated wide interest in sports participation research of different kinds. Generally, it has been shown that participation in sport has been rising since the 1970s (Pilgaard, 2010; Scheerder and Vos, 2011; Stamatakis and Chaudhury, 2008; Stamm and Lamprecht, 2010; Statistics Sweden, 2009). Due to the related expansion of sports provision and participation opportunities, however, attention must be paid to a diversifying tendency in contexts and preferences for sport and physical activity behaviour (Scheerder et al., 2005; Van Bottenburg et al., 2005). Indeed, the majority of European nations (i.e. Belgium, the Czech Republic, Estonia, France, Germany, Ireland, Luxembourg, Slovakia, Spain and the United Kingdom) are representing a large variety of different contexts to partake in sport (Van Tuyckom, 2011).

Although general sports participation rates have been on the rise over the years, the popularity of different forms has been fluctuating. That is, a first participation wave in the 1970s was due to an increase in club-organised activity, whereas a second rise in sports participation since the 1990s is mainly caused by commitment in non-organised sport (De Knop et al., 1996; Laakso et al., 2008; Scheerder and Vos, 2011). This implies that the current popularity of conventional activities is debated (EC/DGEC, 2010; Kjønniksen et al., 2008; Scheerder and Vos, 2011; Sport England, 2003). Thus, developments in participation patterns seem to be mainly due to the proliferation of alternative and recreational leisure-time activities (Skille, 2005; Tomlinson et al., 2005). In a number of (inter)national studies, this trend comes forward from top-ranked sport activities in the overall population. At present, among different studies it appears that the most popular activities are often sports such as fitness, running, recreational biking, recreational swimming and recreational walking (Breuer et al., 2011; Hylton and Totten, 2008; Kjønniksen et al., 2008; Laub, 2012; Scheerder et al., 2011a; Van Bottenburg et al., 2005). The trend towards higher participation rates in non-organised activities is described by Green (2002) as informalisation. 


\section{Theoretical framework}

The above-mentioned developments can be traced to Crum's (1991) sportisation theory. He stated that social tendencies have generally led to a more diversified sports landscape. This appears from the changing nature of provision and promotion of exercise, as well as from the change in participants' sports and context preferences (Burton et al., 2012; Scheerder et al., 2011a). Consistent with a socio-ecological model (Sallis et al., 2008), differential factors on the individual and social or physical environmental level are used to explain processes of internal differentiation in the overall sports landscape.

At the individual (intra- and interpersonal) level, it has been found that changes in sports participation are related to motives, determinants and personal preferences towards engagement in activities and the institutional context (Breuer et al., 2011; Recours et al., 2004; Wheaton, 2010). Firstly, differences with regard to motivation are found in gender, showing that females are more likely to be affected by enjoyment and social interaction than their male counterparts (Allender et al., 2006; Recours et al., 2004). In addition, relations are found between female participants' motivations for certain forms of leisure activities and their body image or physical and mental health (Allender et al., 2006; Casey et al., 2009; Eime et al., 2010; Pelletier et al., 1995). Regarding the context, boys are more often engaged in traditional sport (Laakso et al., 2008), whereas the majority of females prefer to engage in non-traditional activities (Allender et al., 2006; Kjønniksen et al., 2008). Besides gender differences, it has also been shown that club sports participation decreases with age (e.g. Richards et al., 2007). Consistent with these findings, also people at risk of inactivity (e.g. low-income groups, people with weight concerns or elderly) tend to be more easily attracted by recreational or informal forms of sport (Allender et al., 2006; Burton et al., 2012). These arguments show that the majority of the above-mentioned groups prefer informal, low- or no-cost activities in the neighbourhood (e.g. close to home, outdoor, alone), whereas competition is a less important drive (Burton et al., 2012; Casey et al., 2009).

It is suggested that societal changes have been contributing to the sportisation of society (Crum, 1991). On the one hand, sportisation of sport comes from a junction between values such as professionalisation, commercialisation and mediatisation, which emphasise the competitive character of sports practices. On the other hand, de-sportisation of sport contains values that have contributed to the emergence of lower threshold initiatives in order to guarantee accessibility in sport. Important tendencies that have been contributing to this development are, for example, individualisation (Beck, 1992; Giddens, 1990) aging or medicalisation. In this view, sport is often used for health purposes, social inclusion or pleasure (Crum, 1991). Due to these evolutions, opportunities to participate in sport have expanded. That is, the 'mass sport triangle' as a representation of the large network of sport services in the civic, public and market sector (Scheerder et al., 2011b) shows that opportunities to engage in sport today are numerous. This is the result of the adaption of sport services to societal changes influencing people's sports behaviour and preferences over time.

To sum up, it appears that other social contexts than sports clubs are gaining popularity for several reasons. That is, diverse motivations for participation, the expansion of contexts and services and increasing policy interest in relation to societal trends 
have led to a landscape of multiple and increasingly fragmented and de-traditionalised forms of sport behaviour and provision (Crum, 1991; Moens and Scheerder, 2004; Wheaton, 2010).

As a contribution to sports participation research from a broader perspective, the present study aims to investigate how the described trends are reflected in the sports participation styles of kinesiology students as a distinct section of the sports active population. Following Rogers' (2003) theory on innovation, it is suggested that kinesiology students can be considered as early adopters of innovation in sports participation patterns. This implies that the innovative sports participation styles they adopt tend to be imitated by others in their social environment in a later stage (Scheerder et al., 2005). These stages are quite similar to the diffusion of innovations in sports organisations (e.g. Newell and Swan, 1995; Wolfe, 1994; Zaltman et al., 1973).

This study is part of a repetitive cross-sectional research tradition on the detection of sports participation styles by kinesiology students. A first generation of this research presented the results from 1972 to 1999 (Scheerder et al., 2005). In the present contribution, new styles in sports participation are investigated using identical analyses on data obtained in 2009. Two main research questions are put forward: (1) which basic styles in sports participation can today be observed in kinesiology students; and (2) which major changes have been taking place since the implementation of this time-trend analysis in the 1970s. Results are discussed in relation to previous time intervals and new trends in sports participation.

\section{Methods and materials}

This study builds on a tradition of time-trend analyses in sports participation through stapled cross-sectional research on sports participation styles in kinesiology students since the early 1970s (Scheerder et al., 2005). To ensure comparability with earlier editions, the same methodological and statistical procedures are used. The focus of this study is on the presentation of results obtained in 2009. As a previous edition of this analysis (1972-1999) has already been published by Scheerder et al. (2005), detailed information on the sample and results from the former time intervals is not replicated. An overview of sample sizes of previous time intervals is presented in Table 1.

Table I. Overview of sample sizes in different subgroups of the time-trend analysis (1972-2009).

\begin{tabular}{lcccc}
\hline Subgroup & Males & Females & Total & Response rate \\
\hline 1972 & 187 & - & 187 & $100 \%$ \\
$1977 / 76^{\mathrm{a}}$ & 168 & 98 & 266 & $99 \%$ \\
1982 & 111 & 63 & 174 & $87 \%$ \\
$1988 / 93$ & 122 & 89 & 211 & $89 \%$ \\
$1998 / 99$ & 164 & 149 & 313 & $89 \%$ \\
2009 & 95 & 131 & 226 & $55 \%$ \\
Total & 847 & 530 & 1377 & \\
\hline
\end{tabular}

Notes: ${ }^{\text {a }} 977=$ males only; $1976=$ females only. 


\section{Sampling}

The current edition (2009) comprises a sample of 17-24-year-old students in Physical Education (PE) and Kinesiology and Rehabilitation Sciences (further called 'kinesiology students' $)\left(M_{\text {age }}=19.68( \pm 1.86)\right)$. Participants were recruited at the Faculty of Kinesiology and Rehabilitation Sciences at the University of Leuven (Belgium). The sample consisted of 226 first-year students, of whom 95 boys and 131 girls (response rate 55\%). For the first time in this research tradition, more female than male students took part in the survey. This reflects gender-related changes in the observed population of kinesiology students since the last decade. As the response rate for boys and girls was comparable, the sample is proved to be representative for the target group with regard to gender. Moreover, being first-year students at university level, the actual sample was considered homogeneous in terms of other independent variables such as age, social status, geographical location and intensity and frequency of sports participation. Table 2 provides an overview of descriptive statistics on social background and sports participation in the sample. The measure of the socio-economic status (SES) was based on the level of education and the profession of the parents. It must be noted that the observed distribution in SES was operationalised on the sample and can thus not be considered as representative for the overall population. All of the respondents are actively involved in leisure-time sport. A significant difference between male and female students is observed in the average time spent on sports participation per week. Also, girls seem to be significantly more attracted by recreational activities than boys.

The target group was chosen for three reasons. Firstly, kinesiology students generally represent an intense and variegated pattern of sports practices and have a rich tradition in sports participation. A large set of sports practices per person (Table 2) provides the opportunity to investigate patterns in sports participation styles. Secondly, due to their particular interests, they often get in touch with innovation in sports practices at an early stage. This may justify their status as 'early adopters' of sports practices (Rogers, 2003; Scheerder et al., 2005). Thirdly, in their professional field (e.g. as PE teacher, coach, sports manager or physiotherapist) they can be considered as role-models in sports practices. This implies that a broader part of society can later be inspired by their ideas. Although the sample has specific features and cannot be considered as representative for the larger population, the time-trend study of kinesiology students from the perspective as trend setters in sports participation practices can offer knowledge on changing sports participation styles over time.

\section{Instrumentation}

Data were obtained from a standardised retrospective questionnaire on leisure-time sports activities performed in the previous academic year. Leisure-time sport was defined as all club-organised, informally organised or self-organised (e.g. individual, with friends, with family) sports practices performed during leisure time. Mandatory curriculum sport activities were not taken into account. A list of sports practices was provided and could be completed with other sports. The questionnaire was tested for validity and remained the same over years (Scheerder et al., 2005; Vanreusel, 1985). 


\section{Statistical analysis procedures}

Identical to previous stages of this time-trend research (Scheerder et al., 2005), Principal Component Analysis (PCA) was used. PCA is a technique to reduce a diversified number of dimensions in the raw data in order to define patterns, without losing information. By presenting data in a more structured way, similarities and differences can be found (Smith, 2002). This is an exploratory tool, in which the researcher is required to make various decisions (Field, 2009). Therefore, the use of PCA for the analysis procedures of the current study is described in the following paragraphs.

SPSS software (version 19.0) was used to run PCA on reported sports activities, in order to investigate whether the heterogeneous merge of sports practices could be divided into more homogeneous components. Data were classified by dichotomous (yes/no) variables: a person practises a sport (1) or not (0). Although PCA is usually run on metric data, the technique can also be applied to categorical variables as a final analysis procedure (Hair et al., 1995). Sports activities with at least five subjects involved were retained. Because different participation patterns are expected (Table 2), data from male and female students were analysed separately. To maximise the variance of the loadings within the components, Varimax rotation (orthogonal) was used. The final decision about the number of components retained was based on the Kaiser's criterion (eigenvalue of at least 1) and the first breaking point on the corresponding scree-plot.

The final retained components represented groupings of sports that loaded high on one component and could thus be put together as a style or pattern of sports participation. Analogue with techniques used in previous time intervals, a 0.3 cut-off score was set.

Table 2. Background characteristics of 17-24-year-old kinesiology students; anno 2009 (total $N=226$ ).

\begin{tabular}{|c|c|c|c|}
\hline & $\begin{array}{l}\text { Male students } \\
(n=95)\end{array}$ & $\begin{array}{l}\text { Female students } \\
(n=|3|)\end{array}$ & Sign. \\
\hline Mean age (years) & $19.78( \pm 1.84)$ & $19.61( \pm 1.88)$ & NS \\
\hline Response rate & $52.5 \%$ & $56.0 \%$ & NS \\
\hline \multicolumn{4}{|l|}{ Socio-economic status } \\
\hline Low & $34.7 \%$ & $31.5 \%$ & NS \\
\hline Medium & $37.9 \%$ & $33.1 \%$ & NS \\
\hline High & $27.4 \%$ & $35.4 \%$ & NS \\
\hline Participation in leisure-time sport & $100 \%$ & $100 \%$ & NS \\
\hline Participation in club-organised sport & $84.2 \%$ & $71.0 \%$ & NS \\
\hline $\begin{array}{l}\text { Average number of sports practised per person } \\
\text { (diversity) }\end{array}$ & $3.4( \pm 1.70)$ & $3.0( \pm 1.98)$ & NS \\
\hline Average time of sports participation per week (h, min) & $8.7( \pm 5.12)$ & $6.0( \pm 4.97)$ & **** \\
\hline \multicolumn{4}{|l|}{ Level of sports participation } \\
\hline Competitive & $30.5 \%$ & $26.2 \%$ & NS \\
\hline $\begin{array}{l}\text { Recreational } \\
\text { Competitive + recreational }\end{array}$ & $\begin{array}{l}46.1 \% \\
23.4 \%\end{array}$ & $\begin{array}{l}56.0 \% \\
17.8 \%\end{array}$ & NS \\
\hline
\end{tabular}

Notes: NS $=$ Not significant; $* * *=p<.001$. 
This allowed one to retain a minimum number of representative sports activities in the defined patterns, without losing information. Only the highest loading for each sport activity was retained. Variables that did not correlate with one of the defined styles were eliminated. Labelling of the styles relied on the researchers' interpretation of the content of the components; this is substantiated in the Results section.

\section{Results}

PCA produced five components for the male students and four for the female students. Styles were presented in order of the amount of variance explained (variance account for (VAF)) by the component. In a second step, the emerging components were compared to the results of previous time intervals (Scheerder et al., 2005).

\section{Results of the PCA among male kinesiology students}

For the male students, five distinct styles in leisure-time sports participation (total VAF = 0.473 ) have been identified through PCA (Table 3). A local recreational component (VAF $=0.129$ ) came forward as the most pronounced male sport style. This style contains sports that can be practised in an informal, recreational way (e.g. tennis, squash, table tennis, running, swimming and surfing). A second participation style, the component of lifestyle sports $(\mathrm{VAF}=0.096)$, puts together ostentatious and challenging activities. Activities in this style are characterised by meanings related to personal challenge, alternativeness, adventure or extremity, and are often seasonally determined (Salome, 2010; Tomlinson et al., 2005). Those sports were traditionally practised outdoor but have been popularised in recent decades due to indoorised alternatives (Van Bottenburg and Salome, 2010). For example, mountain biking, winter sports, indoor climbing and track and field are represented in this cluster. Due to seasonal characteristics, these sports are convertible between seasons, which can explain their interrelated consistency. The physical health and fitness $(\mathrm{VAF}=0.089)$ component that appeared from the analysis regards aerobic sports activities such as fitness and cycling. It is noteworthy that also running and swimming load relatively high on this component. Furthermore, traditional styles were clustered into two components, with a traditional team $(\mathrm{VAF}=0.083)$ and a traditional individual $(\mathrm{VAF}=$ $0.076)$ style. In general, these styles often contain sports that are usually taught as part of the educational curriculum. Team activities (e.g. soccer, basketball, volleyball) are necessarily practised with others, whereas individual activities (e.g. gymnastics, badminton) can be practised alone or one to one. Both of the traditional components require disciplined training sessions in a particular sports club and often have a competitive goal.

Negative factor loadings on the retained components indicate that a particular sport did not fit within one of the retained components. For the male subgroup, it appears that soccer (classified as traditional team) was inversely related to the component of ostentatiously and challenging sports, as well as to health- and fitness-oriented activities. From a similar perspective, cycling (classified as health- and fitness-oriented) loaded negative on the traditional individual component. Martial arts were dropped in the analysis due to a lack of consistence with one of the presented styles. 
Table 3. Results of the Principal Component Analysis on sports participation styles of male kinesiology students; anno $2009(N=95)$.

\begin{tabular}{|c|c|c|c|c|c|}
\hline Sport disciplines & $\mathrm{Cl}$ & $\mathrm{C} 2$ & $\mathrm{C} 3$ & $\mathrm{C} 4$ & C5 \\
\hline \multicolumn{6}{|c|}{ Component I: Local recreational } \\
\hline Tennis & .742 & .063 & .037 & .084 & .047 \\
\hline Surfing & .614 & .232 & .091 & -.242 & .140 \\
\hline Squash & .603 & .005 & -.366 & .036 & .100 \\
\hline Table tennis & .526 & -.190 & -.262 & .372 & -.221 \\
\hline Swimming & .522 & -.113 & .298 & .162 & -.101 \\
\hline Running & .330 & -.277 & .258 & .237 & -.129 \\
\hline \multicolumn{6}{|c|}{ Component 2: Lifestyle sports } \\
\hline Mountain biking & .102 & .705 & $-.07 \mid$ & -.042 & -.176 \\
\hline Indoor climbing & -.069 & .592 & -.005 & -.093 & -.126 \\
\hline Track and field & -.294 & .580 & -.083 & .394 & .208 \\
\hline Ski/snowboard & .175 & .347 & .099 & -.032 & .119 \\
\hline \multicolumn{6}{|c|}{ Component 3: Physical health and fitness } \\
\hline Fitness & .083 & -.143 & .716 & .186 & .021 \\
\hline Cycling & -.025 & .013 & .509 & .032 & -.431 \\
\hline \multicolumn{6}{|c|}{ Component 4: Traditional team } \\
\hline Soccer & .042 & -.304 & -.615 & .303 & -.200 \\
\hline Basketball & .007 & -.001 & .052 & .626 & .022 \\
\hline Volleyball & .021 & -.202 & -.022 & .597 & .117 \\
\hline \multicolumn{6}{|c|}{ Component 5: Traditional individual } \\
\hline Gymnastics & -.009 & .109 & .166 & .294 & .758 \\
\hline Badminton & .057 & -.243 & -.127 & -.162 & .679 \\
\hline \multicolumn{6}{|l|}{ Dropped variables } \\
\hline Martial arts & -.202 & -.144 & -.067 & -.345 & .102 \\
\hline Variance accounted for (VAF) & 0.129 & 0.096 & 0.089 & 0.083 & 0.076 \\
\hline Eigenvalue & 2.330 & 1.736 & 1.599 & 1.497 & 1.360 \\
\hline
\end{tabular}

\section{Results of the PCA among female kinesiology students}

Regarding female participation styles, four distinct components (total VAF $=0.402$ ) emerged from the analysis (Table 4).

First, a traditional style (VAF $=0.147)$ includes sports such as handball, basketball, soccer, hockey, track and field, and gymnastics. As mentioned earlier, this style is often related to official competition, rankings, membership and fixed training sessions in a sports club. Together with a component of aesthetically oriented activities (different forms of dance and ballet; VAF $=0.095$ ), these first two participation patterns accounted for the highest amount of variance explained. Third, the component of physical health and fitness (VAF $=0.082$ ) consists of recreational activities such as running, aerobics, fitness, swimming and squash. One of the main goals of health-oriented activities is to improve physical health and fitness. The local recreational component (VAF $=0.078$ ) comprises, comparable to the male sample, 'fun sports' that can be performed in a less formal context (e.g. badminton, table tennis, surfing, volleyball). However, it is 
Table 4. Results of the Principal Component Analysis on sports participation styles in female kinesiology students; anno $2009(N=$ I3I).

\begin{tabular}{|c|c|c|c|c|}
\hline Sport disciplines & $\mathrm{Cl}$ & $\mathrm{C} 2$ & $\mathrm{C} 3$ & $\mathrm{C} 4$ \\
\hline \multicolumn{5}{|l|}{ Component I: Traditional } \\
\hline Handball & .799 & .054 & .147 & .066 \\
\hline Basketball & .723 & .038 & .181 & .163 \\
\hline Soccer & .586 & -.062 & .084 & .107 \\
\hline Gymnastics & .576 & .043 & -.122 & -.187 \\
\hline Track and field & .537 & -.088 & -.101 & .009 \\
\hline Hockey & .351 & .001 & .308 & -.128 \\
\hline \multicolumn{5}{|l|}{ Component 2: Aesthetics } \\
\hline Ballet & -.073 & .838 & -.036 & -.128 \\
\hline Dance & -.066 & .831 & -.070 & .134 \\
\hline \multicolumn{5}{|c|}{ Component 3: Physical health and fitness } \\
\hline Running & .154 & -.355 & .352 & .018 \\
\hline Aerobics & -.250 & -.113 & .589 & -.061 \\
\hline Fitness & .136 & -.168 & .483 & .181 \\
\hline Swimming & .098 & .030 & .586 & .066 \\
\hline Squash & .050 & .177 & .531 & -.161 \\
\hline \multicolumn{5}{|c|}{ Component 4: Local recreational } \\
\hline Badminton & .166 & .064 & -.008 & .713 \\
\hline Table tennis & .011 & .081 & -.171 & .645 \\
\hline Surfing & $-.14 \mid$ & -.046 & .241 & .516 \\
\hline Volleyball & .362 & -.130 & -.083 & .393 \\
\hline \multicolumn{5}{|l|}{ Dropped variables } \\
\hline Tennis & -.057 & .085 & .283 & .281 \\
\hline Ski/snowboard & -.094 & -.260 & -.099 & -.109 \\
\hline Variance accounted for (VAF) & 0.147 & 0.095 & 0.082 & 0.078 \\
\hline Eigenvalue & 2.786 & 1.799 & $\mathrm{I} .557$ & 1.486 \\
\hline
\end{tabular}

noteworthy that volleyball equally reaches the retention criterion in the traditional component, whereas hockey also has a high loading on the local recreational component.

In the female analysis, only running showed a highly negative factor loading on the aesthetically oriented component. This implies that dancing is often not combined with running as a leisure-time activity. Ski and snowboard were eliminated from the female analysis due to a lack of consistence with one of the components mentioned before. Also tennis was dropped because of loadings beneath the cut-off score. However, tennis scored relatively high on both the local recreational and the health- and fitness-oriented styles. Further notifications with regard to the (non-)retention of variables will be elaborated in the discussion.

\section{Time trends in sports participation from 1972 to 2009}

The comparison of current findings with results of previous research (Scheerder et al., 2005) allows depicting and interpreting the evolution of sports participation styles from the beginning of the 1970 s to date (2009). In the male (Figure 1) and female (Figure 2) 


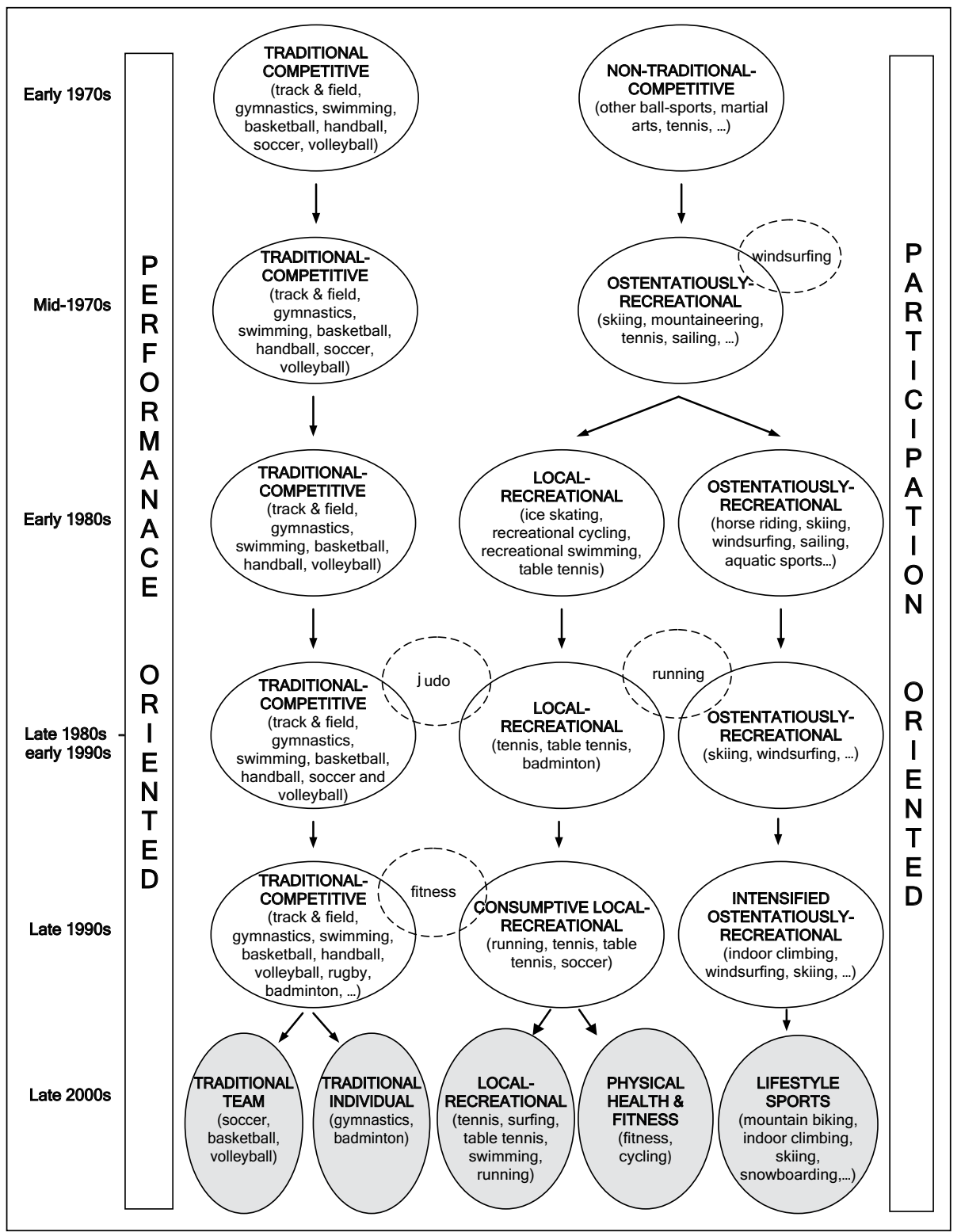

Figure I. Time-trend analysis of sports participation styles in male kinesiology students (1972-2009); elaborated from Scheerder et al. (2005: 425).

component tree, the evolution of a diversifying participation landscape (1972-2009) is visualised. All components or styles are presented within a continuum of performanceoriented sports (i.e. related to traditional organised competition) to participation-oriented sports (i.e. emphasis on social inclusion and/or fun). For both the male and the female results, a short descriptive analysis is provided in the following section. 


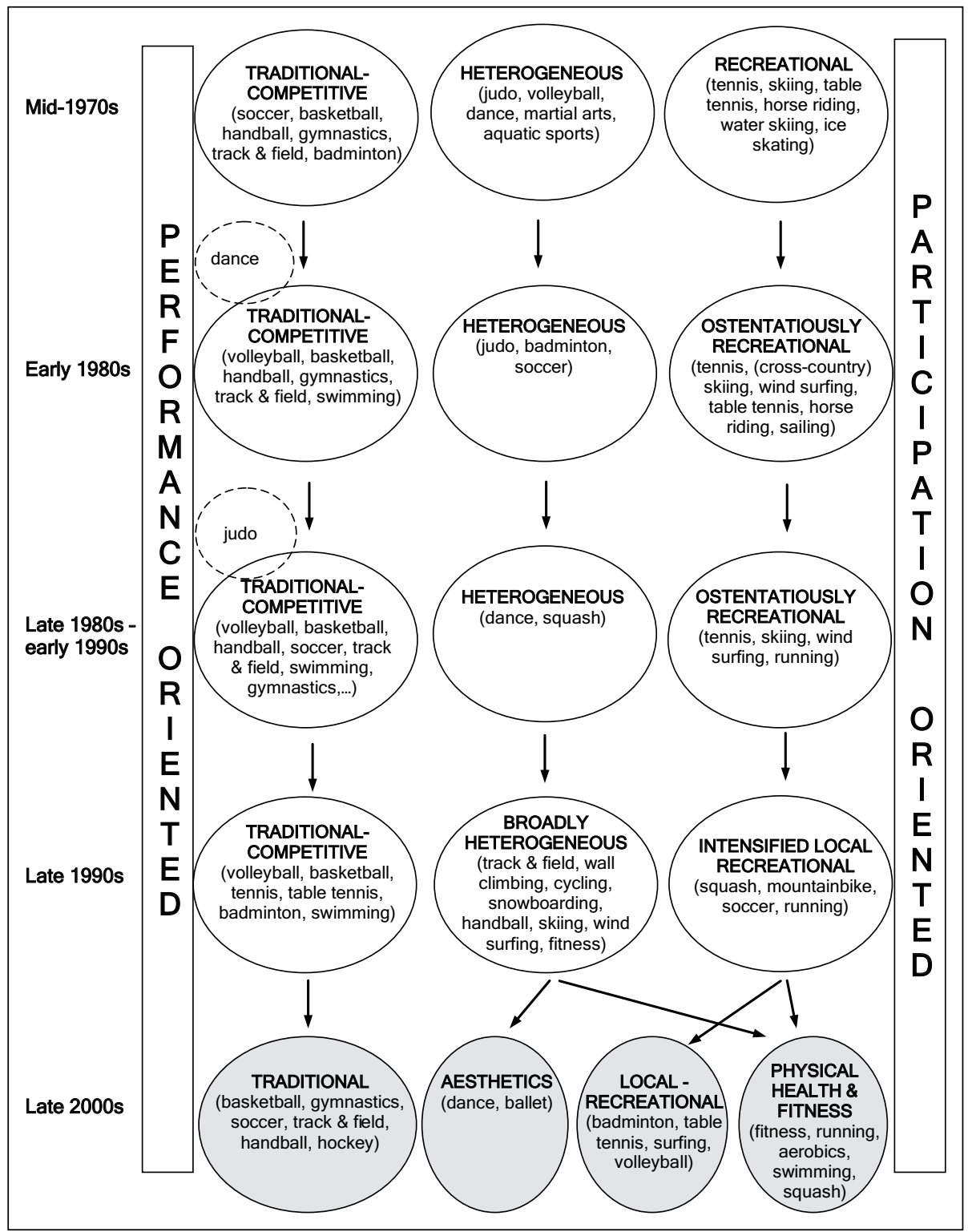

Figure 2. Time-trend analysis of sports participation styles in female kinesiology students (1976-2009); elaborated from Scheerder et al. (2005: 43I).

In male sports participation styles (Figure 1), two main components were observed until the early 1980s: (1) a traditional/competitive component, versus (2) a non-traditional/competitive participation style (Scheerder et al., 2005). The general idea behind this two-fold classification equally dominated the style analysis in more recent decades and has remained useful until today. However, traditional boundaries of the styles have 
been fluctuating due to a more diversifying pathway on the non-traditional side. That is, a clear division of recreational participation styles was observed, with a new health- and fitness-oriented, a local recreational, and a lifestyle component.

A comparable trend was found in female participation styles (Figure 2), with a stable traditional component since the mid-1970s and an intensified crystallised pattern of nontraditional activities since the new millennium. Whereas in earlier years a broadly heterogeneous component was distinguished at the participation side, the 2009 analysis provided a more comprehensive classification of recreational forms. As such, aesthetically oriented activities were found to describe a very specific range of activities. The new health- and fitness-oriented component may refer to girls' participation preferences in leisure-time sport to maintain a healthy body and shape (Allender et al., 2006; Casey et al., 2009; Pelletier et al., 1995).

Not only between components of sports practices, but also within the different components, considerable changes have been taking place over time. Some sports that used to be perceived 'traditional' in the beginning of this time-trend analysis now have been moving to other groupings. For example, in both gender subgroups swimming has been classified in the traditional competitive component until the 1999 analysis. In the current study, swimming is determined in the health- and fitness-oriented or local recreational style. Also volleyball in the female subgroup has expanded from a unique traditional image towards a more local recreational variant. In this view, it is suggested that previous performance-oriented sports today are, besides in its traditional forms, practised in more informal or loose bindings, with emphasis on participation and aims of health and joy. Also fitness, which has only been observed since the late 1990s, has trickled into the health component. A change in participation patterns of particular sports can explain previously observed declines or changes in particular contexts (Scheerder and Vos, 2011).

In both the 2009 male and female subgroups, some components were relabelled due to changes in participation patterns of particular sports. For example, the previously named 'intensified ostentatiously-recreational' component comprised sports that are now classified as lifestyle sports (e.g. mountain biking, skiing, etc.). Their character has changed due to commodification and commercialisation in artificial settings (Salome, 2010). Also the competitive character of traditional sport styles was eliminated, as modes of competition today are also rising in recreational categories. As such, recreational sport participation often pursues competitive goals, in which only 'light' levels of commitment are required (e.g. long-distance running or triathlon without club membership). Nevertheless, regarding the continuum of performance to participation-oriented sports, the traditional competition is still expected to be found at the outer edge of performance-oriented sports.

\section{Discussion}

Stagnation in club sport since the end of the 1990s in combination with an overall rise in sports participation rates (Pilgaard, 2010; Scheerder and Vos, 2011; Sport England, 2003; Stamatakis and Chaudhury, 2008; Stamm and Lamprecht, 2010; Statistics Sweden, 2009) asks for a better understanding of new patterns and tendencies in sport participation. Therefore, the present study aimed to investigate current sports participation styles in a 
group of pioneers or trend setters with regard to sports participation. From Crum's (1991) sportisation theory as an indicator of social change, a fragmented and de-traditionalised spectrum of sports participation styles was expected.

The current sample consisted of 17-24-year-old kinesiology students in Belgium. This sample was defined as an interesting section of the population with regard to sports participation. That is, studying a sample of students that are closely committed to a variegated and innovative pattern of sports practices and trends allows predicting changes in sports participation styles in a broader segment of society (Rogers, 2003; Scheerder et al., 2005). However, they cannot be considered as representative for the Belgian population for the following reasons. Firstly, it must be noted that the adoption of an innovation requires personal interest and values, which means that people can still choose to reject or adopt the presented styles (Rogers, 2003: 38). Secondly, the socioeconomic composition of the sample cannot be considered as representative for the larger population. That is, despite democratisation of education, the majority of university students still represent youngsters from above-average income families (Archer et al., 2003). As a consequence, those students may more easily adopt an omnivore style, indicating that they practise sports in a more frequent, intense and variegated way compared to their peers in the overall population (Peterson, 1992; Taks and Scheerder, 2006; Wilson, 2002). This implies that the target group of kinesiology students can also be seen as an extreme or extraordinary part of the overall population. Moreover, Rogers (2003: 36) states that the adoption of an innovation mostly occurs in groups that are comparable regarding their social status. This may hinder the diffusion of sports practices to other social classes.

Gender differences appeared in the construction of sports participation styles. On the one hand, the diversification of sports participation styles has led to a more comparable pattern of sports participation between boys and girls. Common components concern the traditional, the local recreational and the health- and fitness-oriented style. In this respect, the health- and fitness-oriented style is new compared to previous time intervals. This finding is consistent with existing literature that has proved health-related physical activity to be the most convenient form or motive to be active for women (Allender et al., 2006; Bloom et al., 2005; Casey et al., 2009; Recours et al., 2004). However, scientific literature concerning men's health pursuits through sport participation is scarce. Other gender differences mainly come forward between and within observed components. A first difference was observed in the male lifestyle sports component and the female aesthetically oriented style, still suggesting gender differences in certain types of sports participation (Sanderson, 2001; Thorpe, 2007: 103). Another remarkable fact is that running in the male subgroup is classified in the local recreational component, whereas women's running is part of a group of health- and fitnesspursuing activities. This difference can be a result of different motives for running between men and women (Forsberg, 2012).

Trends observed in the current study can be linked to findings on sports participation in previous research. For example, Tomlinson et al. (2005) already mentioned the emergence of activities that have been challenging the traditional ways of exercising and conceptualising sport. Furthermore, in addition to the high percentage of students being active on a recreational level (Table 2), the newly observed components contain sports 
that are often informally organised, such as recreational swimming, running, biking, mountain biking or skiing (e.g. Breuer et al., 2011; Salome, 2012). Although the results of the PCA do not directly refer to an activity's organisational characteristics, the emergence of these groups of sports practices participation corresponds to the so-called concept of light forms of sport, as introduced by Scheerder and Van Bottenburg (2010). 'Light' practices are supposed to have a lower threshold for participation, are typically practised in an unorganised and informal context, and are characterised by volatility, flexibility and an increased sense of autonomy of the participant (Duyvendak and Hurenkamp, 2004). This implies a lower dependency on formal organisations (e.g. sports clubs) and accommodation. In particular, sports activities from the health- and fitnessoriented or the local recreational components fit within this concept, as they can be easily scheduled in a non- or self-organised way, practised alone or in a light community (i.e. with friends or family) (Scheerder and Van Bottenburg, 2010), using infrastructure with open access. Examples of those 'light' infrastructures are swimming pools, outdoor spaces, streets, bark running tracks or public mountain bike tracks. Public or commercial initiatives often provide open access to those 'short-term' settings where no membership, entrance fees or structural bindings are required. Regarding those activities, an increased sense of autonomy is expected. Autonomy can refer to both the individual decisionmaking in leisure-time activities (Beck, 1992) as well as to the individual nature of particular sports. Consistent to the theory of self-determination (Deci and Ryan, 1985), the interpretation shows that individual choices, social cohesion and a feeling of competency are important values to engage in the most recently observed components.

It is emphasised that the assumption made about the light forms of sport refers to organisational context characteristics. Therefore, further research needs to investigate the contexts of participation in the presented sports participation styles. From the perspective that certain sports today are often practised in a non-organised 'light' setting, two consequences are expected. On the one hand, it is suggested that also sports that were traditionally practised in conventional sports clubs are more often practised in light settings. This can be an explanation for the shift from certain 'traditional club-activities' towards the 'participation-oriented' side of the continuum. On the other hand, activities that were originally practised in a non-organised way are shifting to a more performanceoriented way of exercising (e.g. marathon running or fitness and power competitions).

Due to the diversity of activity types and domains, it is suggested that the sport participation market cannot be targeted as one single market (Kjønniksen et al., 2008; Laakso et al., 2008; Taks and Scheerder, 2006). Compared to the beginning of this timetrend analysis in 1972, it seems that traditional sports activities today have to deal with more different activities that can be practised informally. As this trend is observed as the adoption of an innovation in a group of pioneers/trend setters with regard to sport participation, an extension to other segments of the society is expected to occur. Therefore, it is suggested that the awareness of diversifying trends through segmentation of sports practices can help sports providers to reach different groups more efficiently (Hylton and Totten, 2008). That is, offering programs and opportunities adapted to societal changes and expectations can increase the market share of different segments of sports participants (e.g. outdoor participants, fitness participants, (non-) competitive participants). 
One of the main strengths of the present study is the time-trend comparison with participation styles from the early 1970s, and thus the development of sports participation since the first years of the introduction of the Sport for All policy (Council of Europe, 1975). Nevertheless, some limitations with regard to methodological issues need to be highlighted.

Although the sample proved to be representative for the target group, a notable decline in the response rate in 2009 was observed. Possible explanations for this trend can be found in the literature. It must be noted that the questionnaire in 2009 was extended with supplementary questions used for other sports participation research. However, previous research has shown an inverse relationship between the length of the questionnaire and the response rate (Burchell and March, 1992). Nevertheless, the resulting response rate of $55 \%$ is acceptable as it is comparable to the average response rate of other international research. That is, a comparative analysis of response rates, performed by Baruch (1999) over 175 different studies, showed an average response rate of $55.6 \%$. This argument is also supported by the trends in response rates in other recent time-trend studies (e.g. Craig et al., 2004; Scheerder and Vos, 2011).

Secondly, the technique of PCA partially relies on decisions made by the researchers in the methodological stage and the interpretation of the results. That is, one of the main difficulties of this analysis is the identification of the retention criterion for the number of components. Also the cut-off score for factor loadings is subject to discussion between authors (Field, 2009). In this study, the decision on the cut-off score was influenced by previous techniques in order to ensure comparability with other points in time. Subsequently, also the labelling of the components is part of the researchers' interpretation process, which puts together different sports under 'umbrella terms'. This implies that some clarifications are needed. Firstly, some factors revealed from the analysis are not fully consistent with the original image of a sport. For example, track and field's classification in the boys' lifestyle component is somewhat surprising because of its conventional and competitive character. Nevertheless, due to the seasonal characteristics of track and field, it is hypothesised that students may combine this sport with other 'interchangeable' seasonal sports (e.g. skiing, snowboarding or mountain biking), which may clarify the internal consistency of sports practices within this component. Another possible explanation is that licensed athletes in certain disciplines of track and field (e.g. cross-country running, ultra-trial, orienteering, etc.) can be equally interested in other 'outdoor' activities. However, data of the present study do not allow identifying disciplines practised within track and field. Secondly, some sports exceed the retention criteria on multiple factors. To prevent the analysis from double counting, variables were only retained in the component with the highest factor loading. However, variables with multiple factor loadings exceeding the cut-off score show that one sport can belong to different styles (e.g. track and field, table tennis (Figure 1); volleyball, hockey (Figure 2)). On the contrary, some sports were dropped out due to factor loadings below 0.3 , but they showed a relatively high consistency with one or more components (e.g. tennis in the female subgroup). 


\section{Conclusion}

The present analysis supported the idea of the sportisation and de-sportisation of the sports landscape (Crum, 1991). Consistent to the de-traditionalisation of sports practices (Moens and Scheerder, 2004), it comes forward that newly observed components represent multiple and increasingly fragmented forms of sports participation, challenging the traditional way of exercising. This implies that the classic dichotomy between traditional (performance-oriented) and non-traditional (participation-oriented) cannot be maintained. However, the diversified landscape is expected to be able to attract people from different social layers or with different physical abilities. Therefore, knowledge of motives and specific characteristics of participants in the newly observed styles can support sports providers and governmental institutions in their strategic planning, policymaking and promotion of sport and physical activity towards different segments of society.

\section{Acknowledgements}

This paper was presented at the 9th Conference of the European Association for the Sociology of Sport (EASS) in 2012. We are indebted to the colleagues who commented the paper at that occasion. We are also grateful to the reviewers for their valuable comments and suggestions on the first draft of this paper.

\section{Funding}

This research received no specific grant from any funding agency in the public, commercial or not-for-profit sectors.

\section{References}

Allender S, Cowburn G and Foster C (2006) Understanding participation in sport and physical activity among children and adults: A review of qualitative studies. Health Educational Research 21(6): 826-835.

Archer L, Hutchings M and Ross A (2003) Higher Education and Social Class: Issues of Exclusion and Inclusion. London: RoutledgeFalmer.

Baruch Y (1999) Response rate in academic studies. A comparative analysis. Human Relations 52(4): 421-438.

Beck U (1992) Risk Society: Towards a New Modernity (Theory, Culture and Society). London: SAGE.

Bloom M, Grant M and Watt D (2005) Strengthening Canada: The socio-economic benefits of sport participation in Canada. Report, The Conference Board of Canada, Ottawa, ON, Canada, August.

Breuer C, Hallmann K and Wicker P (2011) Determinants of sports participation in different sports. Managing Leisure 16(4): 269-286.

Burchell B and March C (1992) The effect of questionnaire length on survey response. Quality \& Quantity 26(3): 233-244.

Burton NW, Khan A and Brown WJ (2012) How, where and with whom? Physical activity preferences of three adult groups at risk of inactivity. British Journal of Sports Medicine. Epub ahead of print 20 January 2012. DOI: 10.1136/bjsports-2011-090554. 
Casey MM, Eime RM, Warren RP, et al. (2009) Using a socio-ecological approach to examine participation in sport and physical activity among rural adolescent girls. Qualitative Health Research 19(7): 881-893.

Council of Europe (1975) European Sport for All Charter. Strasbourg: Council of Europe.

Craig CL, Russel SJ, Cameron C, et al. (2004) Twenty-year trends in physical activity among Canadian adults. Canadian Journal of Public Health 95(1): 59-63.

Crum B (1991) Over versporting van de samenleving: Reflecties over de bewegingsculturele ontwikkelingen met het oog op sportbeleid [The Sportification of the Society: Reflections upon the Movement-Cultural Developments with a View to Sport Policy]. Rijswijk: Ministry for Welfare, Public Health \& Culture.

De Knop P, Van Meerbeek R, Vanreusel B, et al. (1996) Sports clubs in crisis? The Flemish situation. European Journal of Sport Management 2: 36-52.

Deci EL and Ryan RM (1985) Intrinsic Motivation and Self-Determination in Human Behavior. New York: Plenum.

Duyvendak JW and Hurenkamp M (2004) Kiezen voor de kudde: Lichte gemeenschappen en de nieuwe meerderheid [Choosing for the Flock: Light Communities and the New Majority] (Kennis, Openbare Mening en Politiek). Amsterdam: Van Gennep.

EC/DGEC (2010) Sport and Physical Activity (Special Eurobarometer 334/Wave 72.3). Brussels: European Commission/Directorate-General for Education and Culture.

Eime RM, Payne WR, Casey MM, et al. (2010) Transition in participation in sport and unstructured activity for rural living adolescent girls. Health Education Research 25(2): 282-293.

Field A (2009) Discovering Statistics Using SPSS. 3rd ed. London: SAGE.

Forsberg P (2012) Motionsløbere i Danmark. Portræt af danske motionsløbere [Recreational runners in Denmark. A portrait of Danish recreational runners]. Report, Danish Institute for Sports Studies, Denmark, January.

Giddens A (1990) The Consequences of Modernity. Stanford, CA: Stanford University Press.

Green K (2002) Lifelong participation, physical education and the work of Ken Roberts. Sport Education and Society 7(2): 167-182.

Hair JF, Anderson RE, Tatham RL, et al. (1995) Multivariate Data Analysis with Readings. New York: Macmillan Publishing Company.

Hylton K and Totten M (2008) Community sports development. In: Hylton K and Bramham P (eds) Sports Development: Policy, Process and Practice. 2nd ed. London/New York: Routledge, pp. $77-117$.

Kjønniksen L, Torsheim T and Wold B (2008) Tracking of leisure time physical activity during adolescence and young adulthood: A 10-year longitudinal study. International Journal of Behavioral Nutrition and Physical Activity 5: 69.

Laakso L, Telama R, Nupponen H, et al. (2008) Trends in leisure time physical activity among young people in Finland, 1977-2007. European Physical Education Review 14(2): 139-155.

Laub TB (2012) Danskernes motions- og sportsvaner 2011. Et overblik [Danish exercising and sporting habits 2011. An overview]. In: 2nd Idrættens største udfordringer [Idrættens biggest challenges to sport Conference], Vejen, Denmark, 30 May. Available at: http://www.idan.dk/da/Nyheder/a218konferenceoplaeg.aspx.

Moens M and Scheerder J (2004) Social determinants of sports participation revisited. The role of socialization and symbolic trajectories. European Journal for Sport and Society 1(1): 35-49.

Newell S and Swan J (1995) The diffusion of innovations in sport organizations: An evaluative framework. Journal of Sport Management 9(3): 317-333. 
Pelletier LG, Fortier MS, Vallerand RJ, et al. (1995) Toward a new measure of intrinsic motivation, extrinsic motivation, and amotivation in sports: The Sports Motivation Scale (SMS). Journal of Sport \& Exercise Psychology 17(1): 35-53.

Peterson R (1992) Understanding audience segmentation: From elite and mass to omnivore and univore. Poetics 21(4): 243-258.

Pilgaard M (2010) How respondents reply to questions about sports participation (Paper presented at the 7th conference of the European association for the sociology of sport (EASS), Porto, Portugal, 5-9 May 2010). Portuguese Journal of Sport Sciences 10(1): 55.

Recours RA, Souville M and Griffet J (2004) Expressed motives for informal and club/association-based sports participation. Journal of Leisure Research 36(1): 1-22.

Richards R, Williams S, Poulton R, et al. (2007) Tracking club sport participation from childhood to early adulthood. Research Quarterly for Exercise and Sport 78(5): 413-419.

Rogers EM (2003) Diffusion of Innovations. New York: Free Press.

Sallis J, Owen N and Fisher E (2008) Ecological models of health behavior. In: Glanz K, Rimer B and Viswanath K (eds) Health Behavior and Health Education: Theory, Research, and Practice. San Francisco: Jossey-Bass, pp. 465-482.

Salome LR (2010) Constructing authenticity in contemporary consumer culture: The case of lifestyle sports. European Journal for Sport and Society 7(1): 69-87.

Salome LR (2012) Indoorising the outdoors: Lifestyle sports revisited. $\mathrm{PhD}$ Thesis, Utrecht University, The Netherlands.

Sanderson P (2001) Age and gender issues in adolescent attitudes to dance. European Physical Education Review 7(2): 117-136.

Scheerder J and Van Bottenburg M (2010) Sport light. De opkomst van lichte organisaties in de sport [The emergence of light organisations in sport]. In: Pattyn B and Raymaekers B (eds) In gesprek met morgen. Lessen voor de eenentwintigste eeuw (series 16). Leuven: Universitaire Pers Leuven, pp. 89-120.

Scheerder J and Vos S (2011) Social stratification in adults' sport participation from a time-trend perspective. Results from a 40-year household study. European Journal for the Sociology of Sport 8(1/2): 31-44.

Scheerder J, Vanreusel B and Taks M (2005) Leisure-time sport among PE students: A time trend analysis of sport participation styles. European Sport Management Quarterly 5(4): $415-441$.

Scheerder J, Vos S, Pabian S, et al. (2011a) Actieve vrijetijdssport in Vlaanderen. Trends, profielen en settings [Active leisure-time sport in Flanders. Trends, profiles and settings]. In: Lievens $\mathrm{J}$ and Waege $\mathrm{H}$ (eds) Participatie in Vlaanderen 2. Eerste analyses van de participatiesurvey 2009. Leuven/Den Haag: Acco Academic, pp. 43-82.

Scheerder J, Zintz T and Delheye P (2011b) The organisation of sports in Belgium. Between public, economic and social profit. In: Sobry C (ed.) Sports Governance in the World: A SocioHistoric Approach. The Organisation of Sport in Europe: A Patch-Work of Institutions, with Few Shared Points. Paris: Le Manuscrit, pp. 84-113.

Skille EA (2005) Individuality or cultural reproduction? Adolescent's sport participation in Norway: Alternative versus conventional sports. International Review for the Sociology of Sport 40(3): 307-320.

Smith LI (2002) A tutorial on principal components analysis. Report, Cornell University, NY. Available at: www.cs.otago.ac.nz/cosc453/student_tutorials/principal_components.pdf (accessed 3 April 2012).

Sport England (2003) Driving Up Participation in Sport: The Social Context, the Trends, the Prospects and the Challenges. London: Sport England. 
Stamatakis E and Chaudhury M (2008) Temporal trends in adults' sports participation patterns in England between 1997 and 2006: The health survey for England. British Journal of Sports Medicine 42: 901-908.

Stamm H and Lamprecht M (2010) Swiss sports participation in an international perspective. European Journal for Sport and Society 8(1/2): 15-29.

Statistics Sweden (2009) Leisure Activities 2006-2007 (Living Conditions 118). Örebro: Statistika Centralbyrån.

Taks M and Scheerder J (2006) Youth sports participation styles and market segmentation profiles: Evidence and applications. European Sport Management Quarterly 6: 85-121.

Thorpe H (2007) Gender. In: Booth D and Thorpe H (eds) Berkshire Encyclopedia of Extreme Sports. Great Barrington, MA: Berkshire Publishing Group, p. 103.

Tomlinson A, Ravenscroft N, Wheaton B, et al. (2005) Lifestyle sports and national sport policy: An agenda for research. Report to Sport England, University of Brighton, UK, March.

Van Bottenburg M and Salome LR (2010) The indoorisation of outdoor sports: An exploration of the rise of lifestyle sports in artificial settings. Leisure Studies 29(2): 143-160.

Van Bottenburg M, Rijnen B and Van Sterkenburg J (2005) Sports Participation in the European Union: Trends and differences. 's-Hertogenbosch/Nieuwegein: W.J.H. Mulier Institute/Arko Sports Media.

Van Tuyckom C (2011) Six sporting worlds: A cluster analysis of sports participation in the EU-25. Quality \& Quantity. Epub ahead of print 28 June 2011. DOI: 10.1007/s11135-011-9528-8.

Vanreusel B (1985) Tijdstrendanalyse van sportdeelnamestijlen [Time trend analysis of sports participation styles]. Non-published PhD Thesis, University of Leuven, Belgium.

Wheaton B (2010) Introducing the consumption and representation of lifestyle sports. Sports in Society 13(7): 1057-1081.

Wilson TC (2002) The paradox of social class and sports involvement: The roles of cultural and economic capital. International Review for the Sociology of Sport 37(1): 5-16.

Wolfe RA (1994) Organizational innovation: Review, critique and suggested research directions. Journal of Management Studies 31(3): 405-431.

Zaltman G, Duncan R and Holbek J (1973) Innovations and Organizations. New York: Wiley. 